\title{
MEMBANGUN KEAKRABAN DAN PERSAUDARAAN PELAJAR INDONESIA YANG BERLANDASKAN NILAI-NILAI KEISLAMAN DI LINGKUNGAN UNIVERSITI MALAYA
}

\author{
Yessi Jusman ${ }^{1)}$, Ahmad Zaki ${ }^{2)}$ \\ ${ }^{1)}$ Program Studi Teknik Informatika, Fakultas Teknik, Universitas Abdurrab \\ ${ }^{2}$ Program Studi Teknik Sipil, Fakultas Teknik, Universitas Abdurrab \\ Surel: yessi.jusman@ univrab.ac.id $^{1)}$ dan $\underline{\text { ahmad.zaki@univrab.ac.id }}^{2)}$
}

\begin{abstract}
Studying abroad has its challenges and its own charm. Feelings of loneliness and confusion often occurs especially for those who are still single or away from their families. Unity students of Indonesia based ukhuwah islamiah named Forum brotherhood of Islamic Studies at Universiti Malaya (FUSI UM) is an organization formed to bring together all students of programs Strata-1 (S1), Strata-2 (S2) and Strata-3 (S3) in University of Malaya. However, the existence of FUSI UM was depended on the current student in the time. Authors contribution is to run up, to follow and to run the activities planned by FUSI UM in the Great Council (MUBES) from 2013 until 2016. These activities are designed to unite and establish ukhuwah islamiah among fellow members. Along the way, FUSI UM has successfully implemented the agendas and activities with the goal of beginning.
\end{abstract}

Keywords: Fraternity, Brotherhood, Student Indonesia, Universiti Malaya, and Activities.

\begin{abstract}
ABSTRAK
Menuntut ilmu di luar negeri memiliki tantangan dan pesona tersendiri. Perasaan kesendirian dan kegalauan sering melanda apalagi bagi mereka yang masih berstatus single atau yang jauh dari keluarga. Persatuan pelajar-pelajar Indonesia yang berlandaskan ukhuwah islamiah yang diberi nama Forum Ukhuwah Studi Islam di Universiti Malaya (FUSI UM) merupakan wadah yang dibentuk untuk menghimpun semua pelajar baik program Strata-1 (S1), Strata-2 (S2) dan Strata-3 (S3) yang ada di lingkungan Universiti Malaya. Namun gaungan FUSI UM bergantung kepada siapa saja pelajar yang ada di UM pada masa tertentu. Untuk tahun 2013, FUSI UM dapat dikatakan mati suri. Kontribusi penulis adalah menggerakkan kembali, menjadi pengurus dan mengikuti dan menjalan kegiatan yang telah direncanakan oleh FUSI UM dalam Musyawarah Besar (MUBES) dari tahun 2013 hingga tahun 2016. Kegiatankegiatan tersebut dirancang untuk mempersatukan dan menjalin ukhuwah sesama anggota. Dalam perjalanannya, FUSI UM telah berhasil melaksanakan agenda dan kegiatan dengan tujuan awalnya.
\end{abstract}

Kata kunci: Persaudaraan, Ukhuwah, Pelajar Indonesia, Universiti Malaya, dan Kegiatan. 
Jurnal Pengabdian Masyarakat

vol.1 no.1 Oktober 2017

\section{PENDAHULUAN}

Belajar di luar negeri adalah usaha untuk meraih masa depan yang lebih baik. Kita menyadari bahwa masa depan seseorang akan sangat dipengaruhi oleh pendidikannya. Dengan belajar di manca negara ini kita akan mendapatkan pengalaman dan wawasan global, wawasan yang lebih luas. Hal ini penting artinya, karena sekarang telah banyak perusahaan internasional yang beroperasi dan universitas di berbagai negara yang bisa memberikan peluang dan sekaligus tantangan bagi kita semua. Dengan wawasan global dan keilmuan yang kita peroleh kita akan dapat berkompetisi secara lebih baik dalam mencari lapangan pekerjaan di dalam maupun luar negeri [1]. Dengan bekal ini kita bisa mendapatkan pekerjaan dengan lebih mudah, walaupun harus bersaing dengan para lulusan dari negara lain, termasuk dari negara-negara maju sekalipun. Disebalik harapan dan cita-cita tadi, dalam kenyataan keseharian mahasiswa yang berlajar di luar negeri mengalami beberapa masalah dan tantangan. Baik masalah perkuliahan, pergaulan, bahkan masalah pribadi yang perlu dibantu oleh orang-orang yang dekat dan dipercaya. Masalah dan tantangan tersebut bisa dikarenakan perbedaan latar belakang, daerah asal, tempat tinggal (rumah sewa dan kos) dan budaya. Oleh karena itu, perlu dibuat sebuah wadah perkumpulan dan persaudaraan yang dibina dalam suatu organisasi yang menampung segala permasalahan dan tantangan diatas.

Forum Ukhuwah Studi Islam Universiti Malaya (FUSI UM) adalah sebuah wadah yang sudah dibentuk untuk menyatukan pelajar-pelajar Indonesia yang berasal dari berbagai daerah yang mana dalam wadah tersebut dirancang kegiatan-kegiatan yang menyatukan dan mempererat persaudaraan dengan dasar ukhuwah keislaman. FUSI didirikan pada tahun 2009. Keberadaan dan gaung FUSI akan dipengaruhi oleh orang-orang yang terikat didalamnya. Keterikatan itu berbeda-beda karena didasari oleh quota pelajar-pelajar Indonesia yang ada berbeda-beda pertahunnya.

Penulis adalah pelajar Indonesia yang ada di lingkungan UM dari tahun 2013 sampai dengan 2016. Selama keberadaan kami di UM, kontribusi yang dijalani yaitu menggerakkan kembali FUSI UM yang dapat dikatakan mati suri. Membina FUSI UM serta mengarahkan berbagai kegiatan telah dijalankan bersama dengan tim pengurus yang telah dibentuk untuk tujuan yang seperti tercantum rinci dalam Anggaran Dasar dan Anggaran Rumah Tangga (AD/ART) FUSI UM.

Menjadi pengurus dan mengelola berbagai kegiatan FUSI UM merupakan wujud dari pengabdian kami sebagai pelajar Indonesia yang berada di lingkungan Universiti Malaya untuk membantu dan menjaga kebersamaan serta mempererat ukhuwah diantara sesama warga negara Indonesia yang sedang berada di negara asing pada periode tertentu dengan melaksanakan berbagai kegiatan. Semangat kebersamaan ini akan terus terjalin walau kami sudah kembali ke tanah air yang mana tersebar diberbagai daerah atau propinsi di Indonesia.

\section{BAHAN DAN METODE}

Pengabdian ini dilaksanakan di Universiti Malaya Kuala Lumpur, Malaysia. Berbagai agenda FUSI UM telah kami rumuskan dan jalankan yang mana detailnya seperti berikut:

1. Kegiatan Tahunan

Untuk kegiatan tahunan ini adalah kegiatan yang dilaksanakan dua kali dalam setahun atau lebih ringkasnya bisa disebut kegiatan semesteran. Kegiatan ini adalah pengajian (biasa disebut Kajian Islam Semasa), doa' dan sholat hajat untuk berhasil mendapat nilai terbaik pada setiap ujian semester. Kegiatan ini diikuti oleh semua pelajar baik laki-laki maupun perempuan. Kegiatan ini merupakan kegiatan yang digawang oleh bidang sumber daya manusia (SDM). Sedangkan kegiatan tahunan yang lainnya adalah buka bersama, pembagian bingkisan hari raya idul fitri dan pembagian daging qurban untuk masyarakat Indonesia yang berada di lingkungan UM baik pelajar maupun pekerja 
cleaning servis (CS). Kegiatan-kegiatan tersebut digawang oleh bagian Sosial Masyarakat (SosMas).

2. Kegiatan Bulanan

Kegiatan bulanan adalah kegiatan yang dilakukan setiap bulannya yaitu kegiatan pengajian serta malam bina iman dan taqwa (MABIT) bagi pelajar-pelajar laki-laki. Kegiatan ini digawang oleh bidang SDM. Kegiatan bulanan yang lainnya adalah kegiatan pengajian untuk pekerja CS yang digawang oleh bidang Sosmas. Pengajian CS ini bertujuan untuk menjalin keakraban dan persaudaraan dengan masyarakat Indonesia lainnya yang bekerja di Universiti Malaya.

3. Kegiatan Mingguan

Kegiatan mingguan adalah kegiatan pembinaan untuk pelajar-pelajar yang dilaksanakan per minggunya. Biasanya kegiatan ini dibagi perkelompoknya sekitar 5-10 orang setiap kelompok. Kegiatan ini sudah terprogram diawal semester untuk kegiatan per minggunya. Tempat acara kegiatan ini biasanya di daerah sekitar lingkungan kampus UM ataupun berdasarkan kesepakatan bersama. Kegiatan ini selain menjalin keakraban dan ukhuwah juga membicarakan beberapa hal seputar perkuliahan, penelitian dan kemajuan penulisan skripsi, thesis dan disertasi.

\section{HASIL DAN PEMBAHASAN}

Dalam pelaksanaan kegiatan-kegiatan pengabdian selama tergabung dalam FUSI UM tersebut pada bagian bahan dan metode, kami telah mempublikasikan beberapa acara melalui grup washap dan facebook yang telah dibentuk untuk memudahkan komunikasi. Sehingga hasil yang dapat ditunjukkan pada karya tulis ini adalah berupa foto-foto kegiatan yang telah diceritakan pada bagian sebelum ini.

Gambar 1 adalah kegiatan pengajian untuk pelajar yang diadakan setiap semester yang mana dilakukan pada saat sebelum ujian semester berlangsung. Kegiatan ini disebut dengan Kajian Islam Semasa. Biasanya diadakan pada hari kerja (senin sampai juma't) dan pernah juga dilaksanakan pada hari libur mingguan (yaitu sabtu atau minggu) tergantung pilihan waktu yang telah disurvei yang mana waktu kebarangkalian banyak yang bisa datang. Setelah pengajian tersebut langsung dilanjutkan dengan sholat hajat untuk mendapatkan nilai yang terbaik untuk ujian semester. Pengajian ini diisi oleh narasumber-narasumber pilihan seperti penulis buku terlaris Nuruddin Zanki dan perang salib oleh ustadz Al habib Alwi Alatas (Alumni Madinah), Ustadz M. Choirin (Alumni Al azhar Mesir), Ustadz Muhammad Yusuf (Phd student Universitas Islam Antar Bangsa), Ustadz Rio Erismen (Alumni Mesir dan juga pernah menjadi pimpinan redaksi majalah Dakwatuna) serta ustadz lainnya.

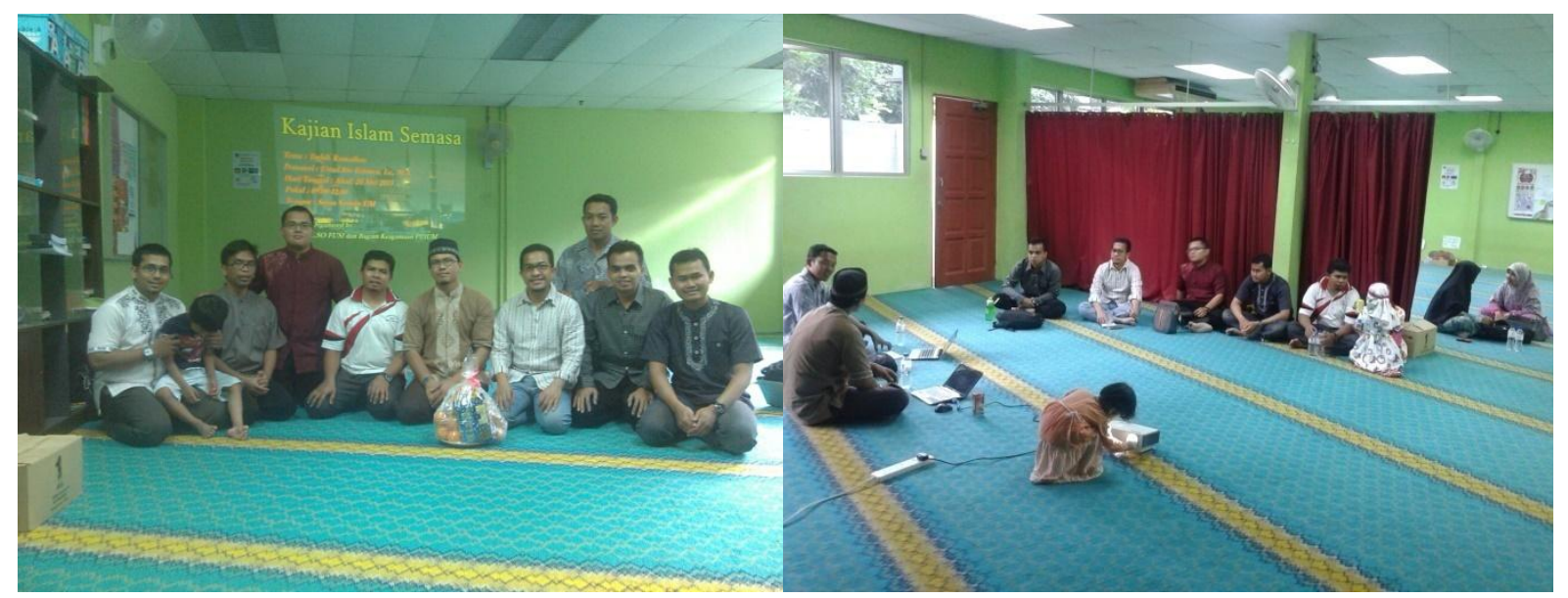


Jurnal Pengabdian Masyarakat vol.1 no.l Oktober 2017
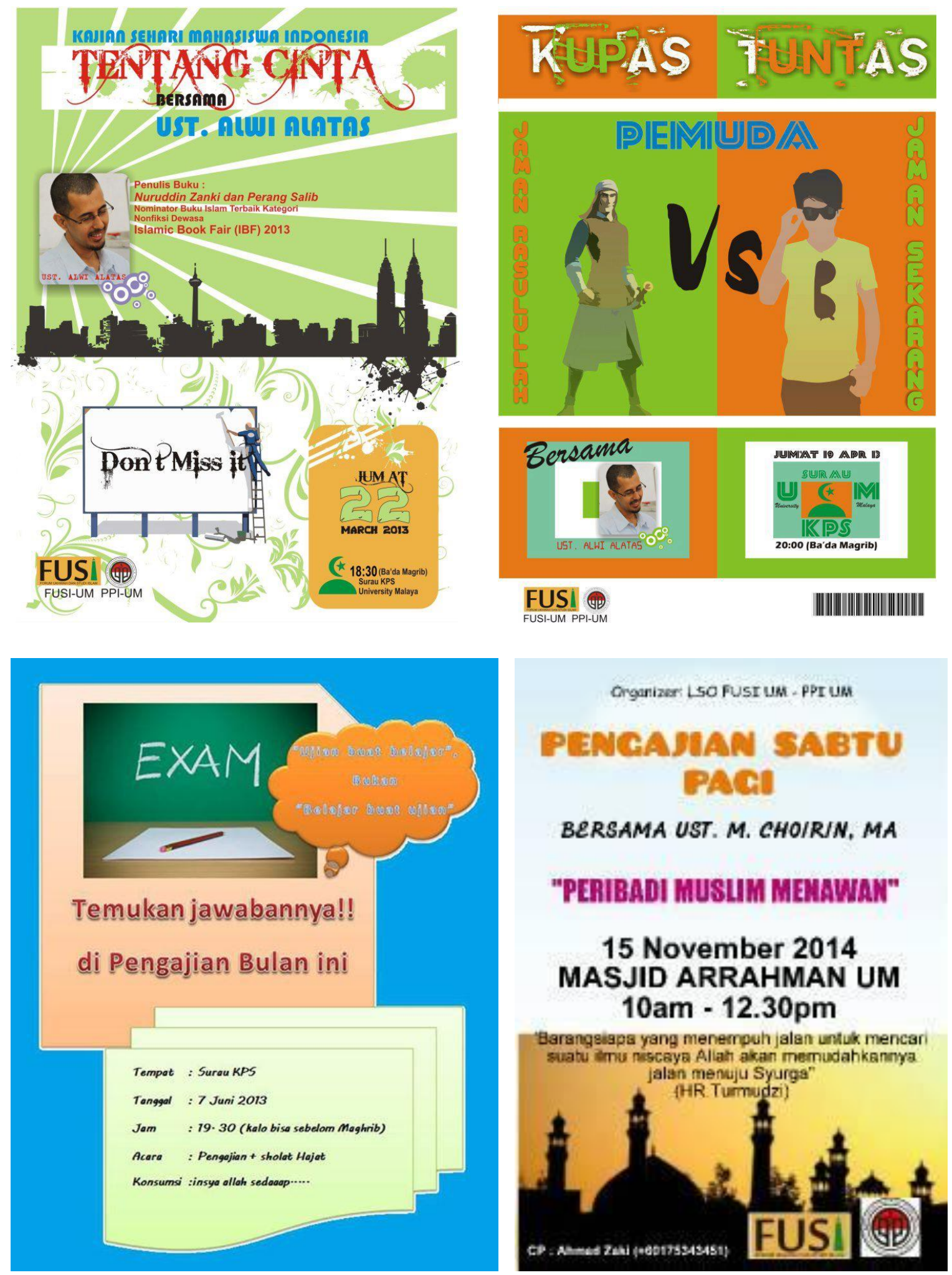

Gambar 1. Kajian Islam Semasa setiap semester sebelum ujian semester 


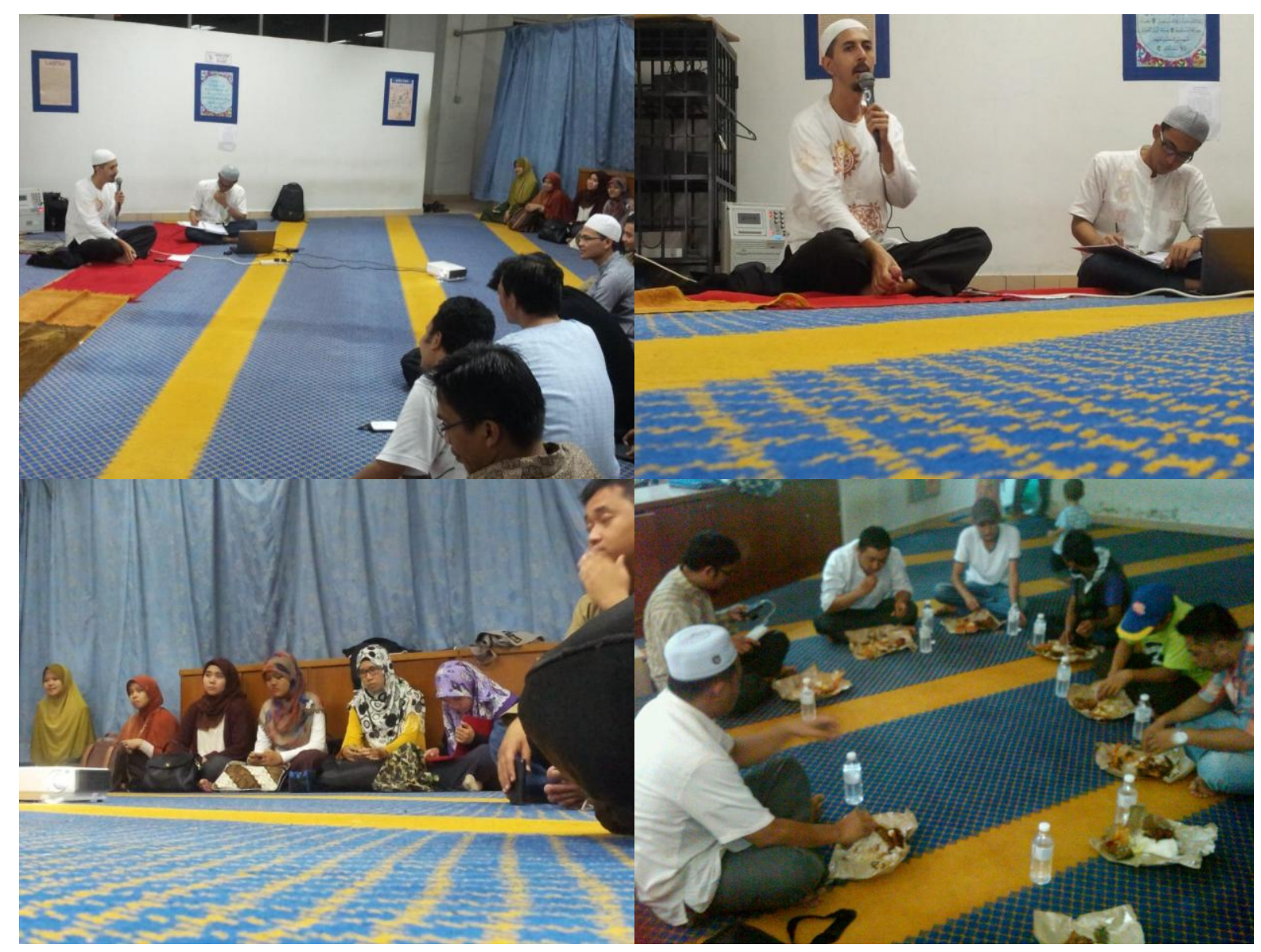

Gambar 1. Lanjutan

Kegiatan tahunan lainnya adalah acara yang bersifat besar yang diadakan setiap tahunnya. Acara yang pernah dilakukan adalah seminar-seminar dengan topik yang sedang meluas dibicarakan oleh umat islam se-indonesia dan bahkan se-dunia. Seperti seminar tentang trans gender yang menjadi isu besar dan membahayakan untuk umat islam dan generasi penerus bangsa kedepannya. Acara besar ini juga ada yang diangkatkan bersamasama dengan organisasi-organisasi persatuan lainnya di Malaysia seperti acara membangun jembatan masa depan yang dilaksanakan bertepatan pada hari buruh 1 May. Acara setiap tahun pada hari buruh tersebut merupakan acara besar tahunan Forum Ukhuwah Muslimah Indonesia se-Malaysia (FOKMA). Untuk acara besar FOKMA 1 May 2016, FOKMA bekerjasama dengan FUSI UM yang tergabung dalam kepanitiaan besar (100 orang) yang mana total peserta sebanyak lebih kurang 800 orang. Total peserta tersebut adalah warga negara Indonesia yang tersebar di Malaysia yang mana mereka adalah pelajar, pekerja pabrik, dosen di universitas yang ada di Malaysia, bahkan ibu rumah tangga. 

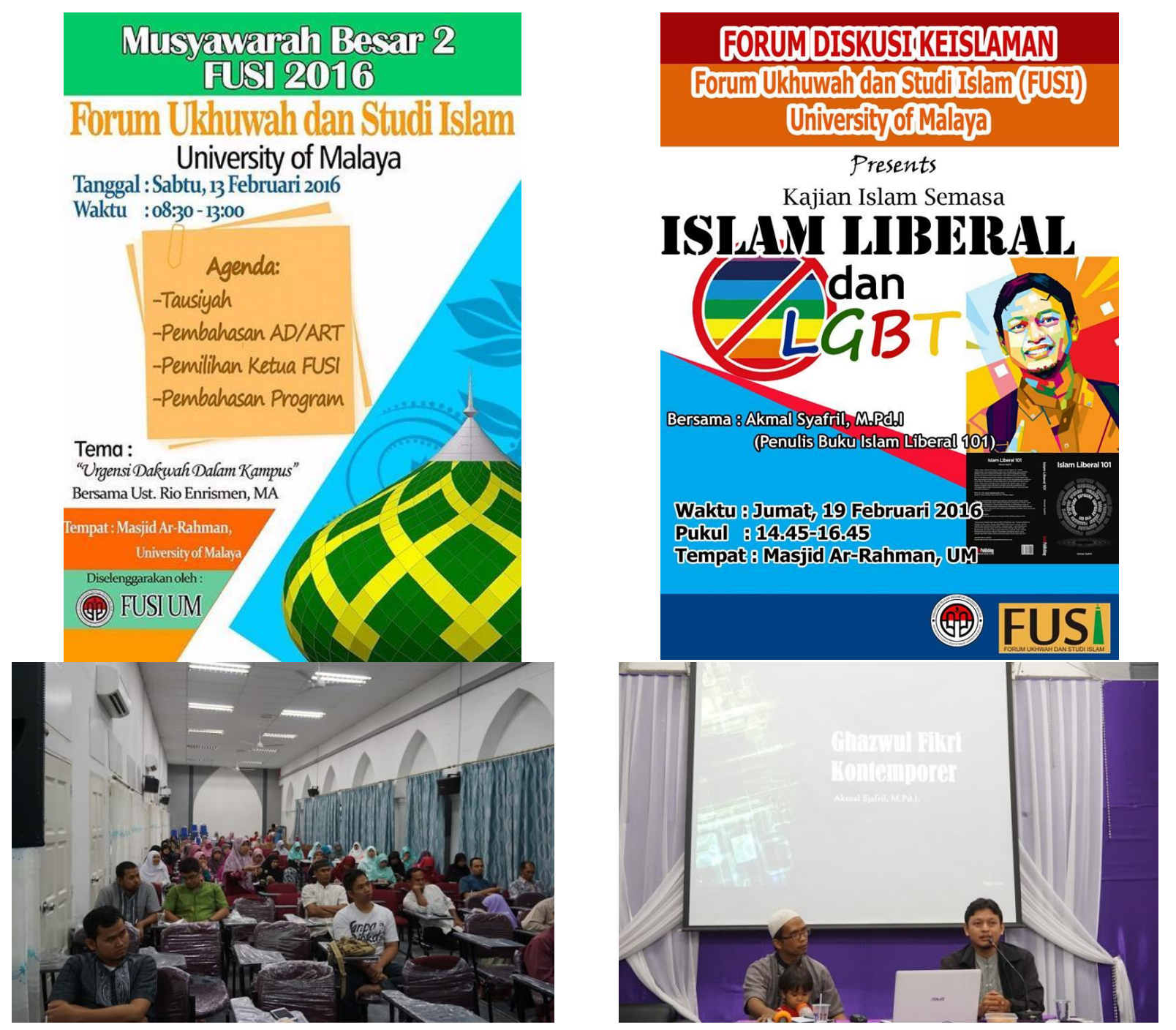

Gambar 2. Seminar tahunan dengan isu yang sedang hangat di dunia keislaman

Kondisi ini menginspirasi para pelajar Indonesia untuk mendiskusikan permasalahan seputar islam liberal dan LGBT, dan berusaha mencarikan solusi bagi permasalahan yang muncul akibat isu tersebut. Forum Ukhuwah Studi Islam dan Persatuan Pelajar Indonesia di Universitas Malaya (FUSI UM dan PPI UM) menggelar diskusi intelektual atau Forum Group Discussion (FGD) yang dipandu oleh Saudara Akmal Sjafril sebagai nara sumber. Pembicara dalam forum diskusi ini merupakan seorang penulis buku Islam Liberal 101 yang juga membahas permasalahan islam liberal dan perkembangannya di tanah air [2].

Dari diskusi ini, ada beberapa informasi yang dapat dirangkumkan:

1. Isu-isu seputar islam liberal dan LGBT merupakan salah satu serangan pemikiran (Ghwazul Fikr) dari orang orang yang ingin menghancurkan pemahaman islam dan generasi islam masa depan.

2. Pergerakan kedua isu besar ini telah merambah di kalangan masyarakat bawah, menengah, atas, bahkan kepada kaum intelektual.

3. Kasus LGBT ini bukanlah hal yang tabu di kalangan pekerja, bahkan ada beberapa kasus yang mencengangkan di kalangan tenaga pabrik.

4. LGBT bukanlah sebuah hal yang terjadi secara tidak sengaja. Tidak ada pembuktian ilmiah yang mendukung LGBT sebagai bawaan genetik. Ia merupakan sebuah penyimpangan yang dipengaruhi oleh pola asuh di keluarga dan masyarakat. 
5. Para orang tua memiliki peran yang sangat penting, untuk mendampingi anak-anak, dan memberikan pemahaman semenjak dini tentang gender mereka dan batasan-batasan berinteraksi dengan teman yang sejenis, maupun yang berlawanan jenis.

6. Para orang tua diharapkan berpartisipasi aktif ketika seorang anak mulai menunjukkan kelainan pada gender yang seharusnya, semisal anak lelaki yang gemulai, atau kecenderungan terhadap sesama jenis, agar dapat diberikan pemahaman dan pendidikan tentang seharusnya mereka bersikap.

7. Orang tua harus lebih selektif dalam memilihkan informasi yang akan diterima anak, terutama dari media-media internaiment dan lingkungan sekitar.

Diharapkan dari diskusi ini, peserta mendapatkan ilmu dan solusi terhadap kedua isu besar yang tengah melanda Indonesia dan juga negara-negara lain di dunia.

Kegiatan yang juga tahunan yang mana lebih ditargetkan untuk pelayanan dan kepedulian pelajar-pelajar Indonesia yang tergabung dalam FUSI UM kepada pekerja buruh CS yang bekerja di lingkungan UM. Mereka merupakan rakyat Indonesia yang merantau jauh mencari nafkah untuk keluarga. Ada diantara mereka yang bahkan sampai meninggalkan anak (yang sedang sekolah dari sekolah menengah sampai ke tingkat perguruan tinggi) di Indonesia dengan orang tua atau keluarga, hanya sekedar untuk mencari uang untuk kelanjutan masa depan dan pendidikan anak-anak mereka. Dengan landasan itulah, kami pelajar Indonesia yang tergabung dalam kepengurusan FUSI UM berusaha mencarikan donatur dengan membuat proposal untuk menggalang kegiatan pelayanan berupa acara berbuka bersama di bulan ramadhan, pembagian bingkisan idul fitri, serta pembagian daging qurban di hari raya idul adha. Mereka sangat menghargai usaha dan kebersamaan ini seperti terlihat pada Gambar 3.
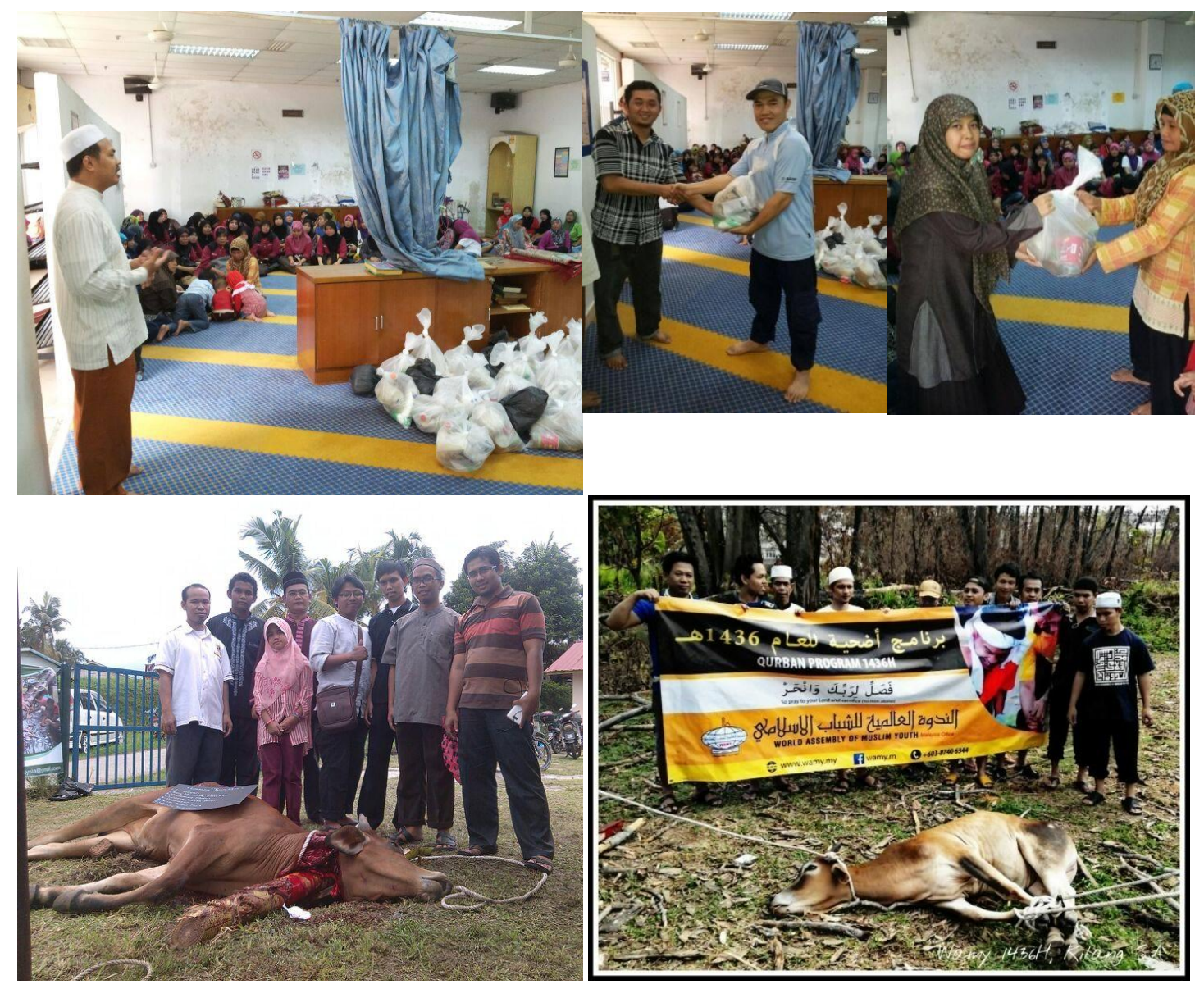


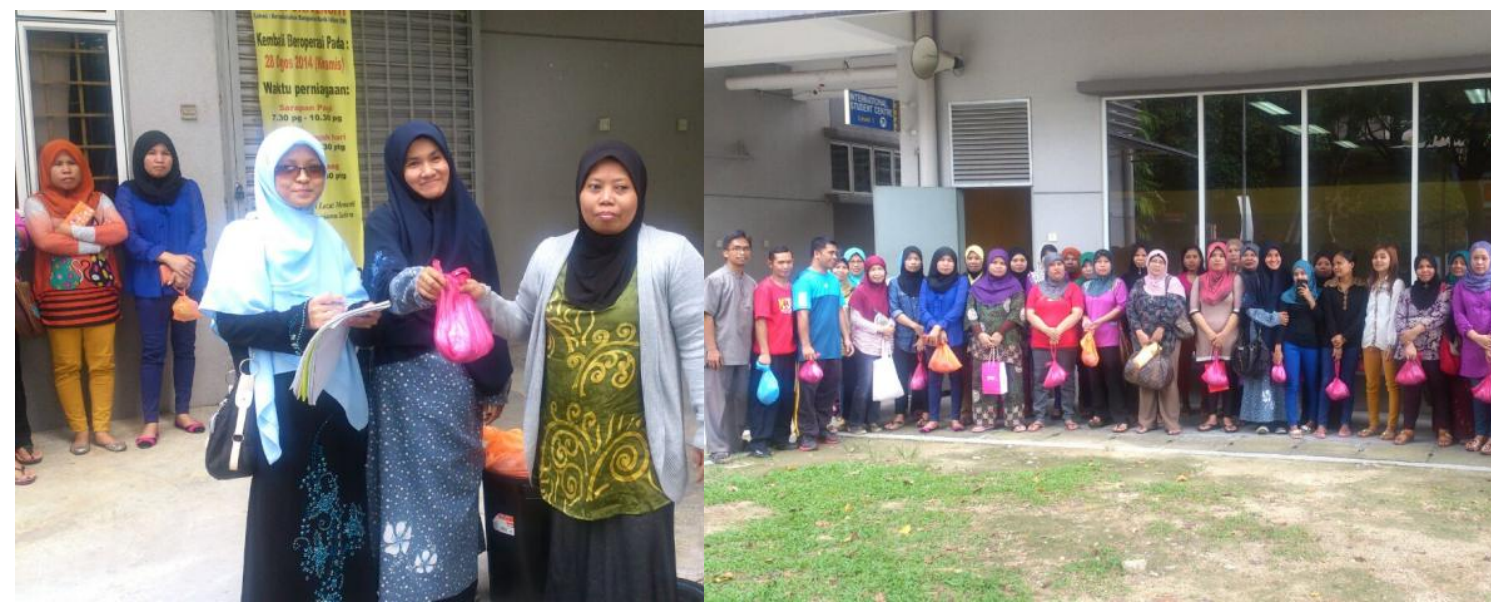

Gambar 3. Kegiatan Pelayanan Tahunan untuk pekerja buruh CS di lingkungan UM

Kegiatan selanjutnya adalah kajian yang dilaksanakan untuk seluruh pengurus setiap 2-3 bulan. Kegiatan ini dilakukan agar setiap pengurus bertambah erat tali persaudaraan dengan diisi bekal kerohanian. Kegiatan ini dilakukan dihari libur mingguan yaitu sabtu atau minggu.

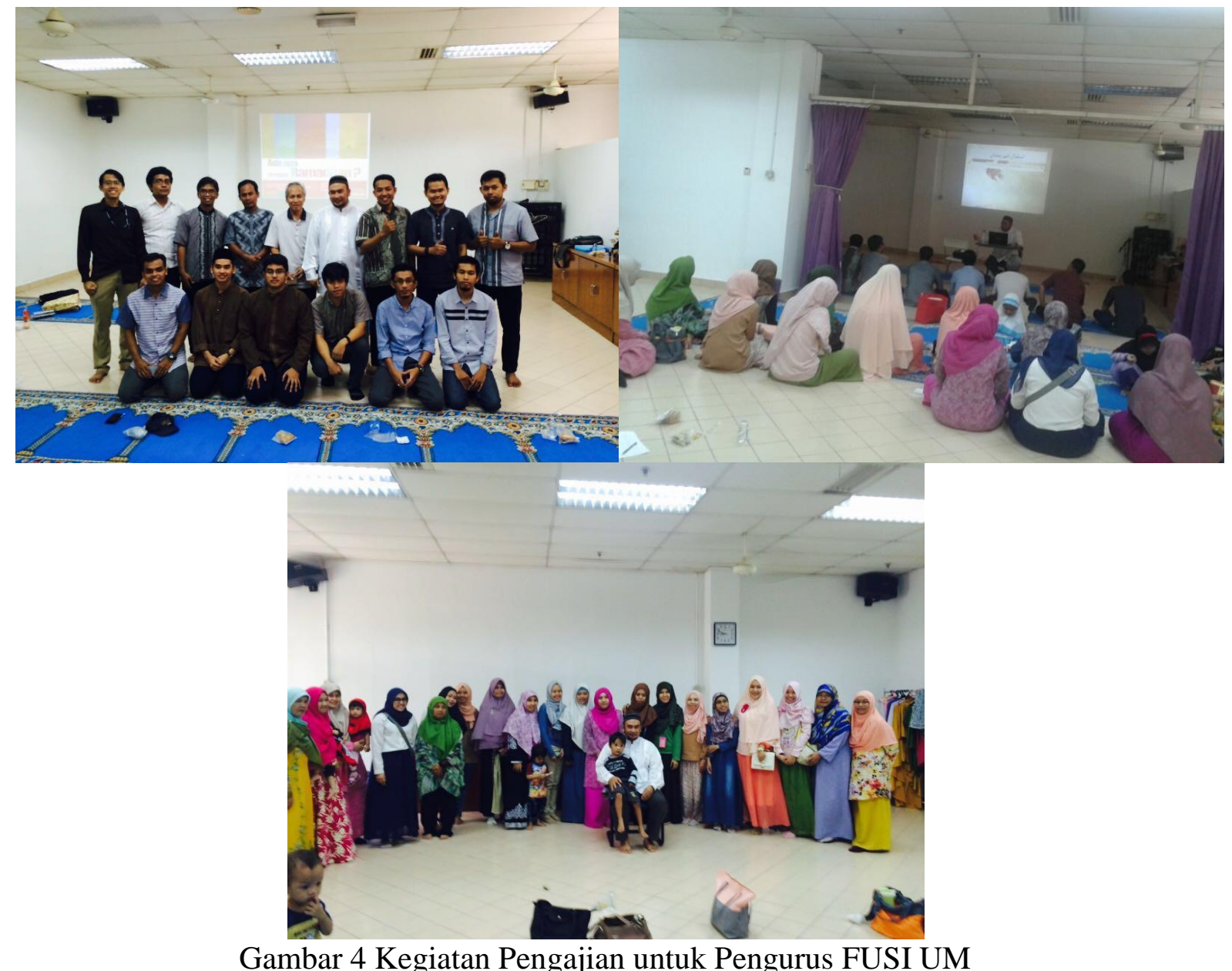

Acara bulanan dan mingguan lainnya adalah acara pengajian bulanan untuk pekerja CS, olahraga kebersamaan dan acara keputrian untuk pelajar-pelajar perempuan. Acara 
tersebut dilaksanakan dengan baik. Rata-rata kehadiran pelajar perempuan tidak begitu ramai dikarena lingkungan UM yang begitu besar sedangkan acara keputrian dilaksanakan dihari juma't yang mana di jam istirahat hari kerja. Kebanyakan pelajar Indonesia adalah pembantu peneliti untuk dosen di UM sehingga keterbatasan waktu dan jarak menjadikan keterbatasan yang hadir. Namun untuk pengajian pekerja CS yang dilaksanakan selalu dihadiri oleh ramai CS sampai kami membuat pembagian 3 waktu dalam satu hari untuk pekerja-pekerja yang menjadi CS di fakultas-fakultas berlainan. Total CS yang ikut rata-rata 100 orang CS. Sedangkan untuk pelajar laki-laki, olahraga Futsal sering diadakan di hari cuti sabtu atau minggu dengan tujuan kebersamaan dan keakraban. Kegiatan terlaksana seperti pada Gambar 5 .

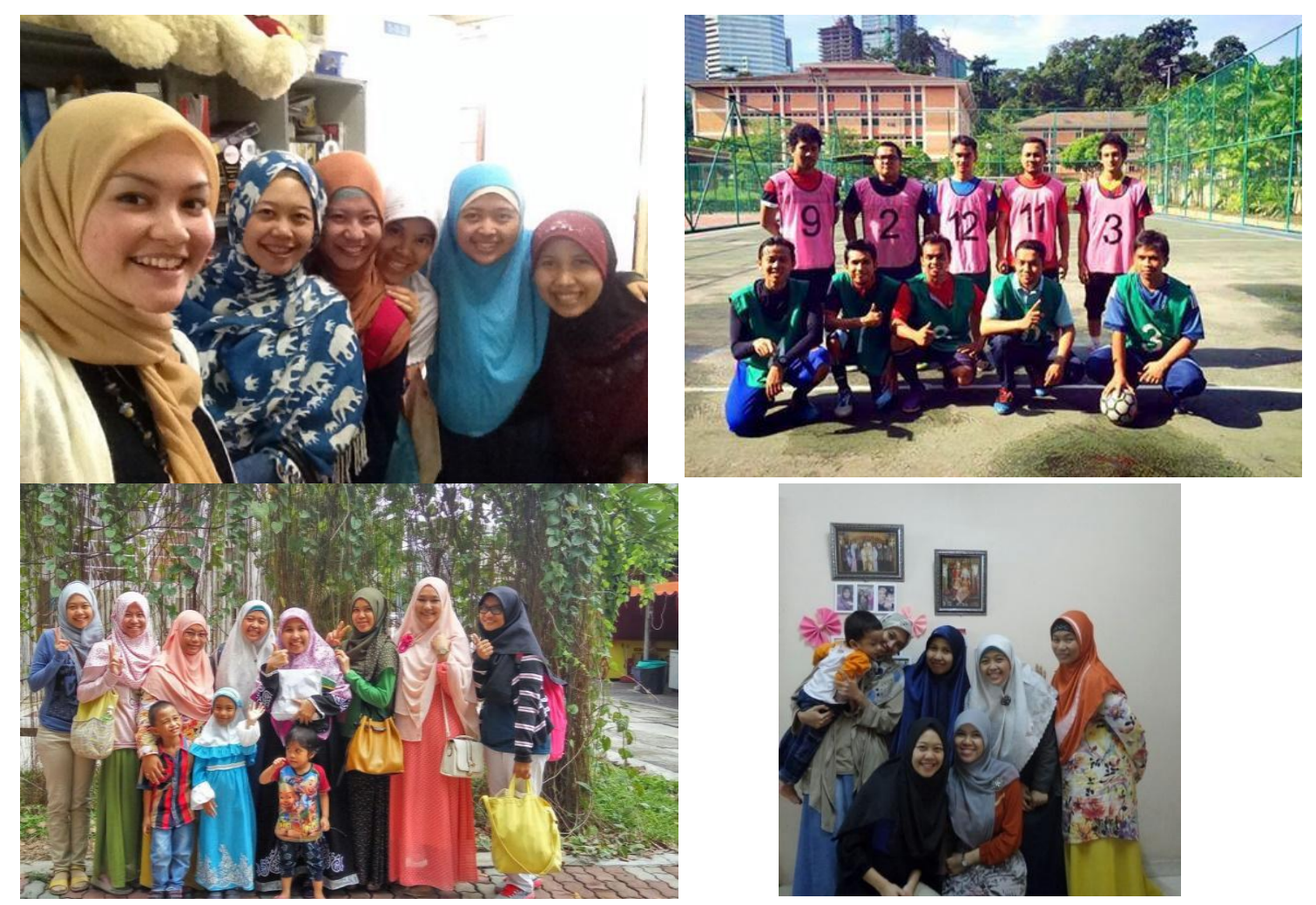

Gambar 5. Kegiatan Bulanan Pengajian Pekerja CS, Olahraga Kebersamaan, dan Mingguan Keputrian

\section{KESIMPULAN}

Pengabdian yang dilaksanakan selama tergabung dalam FUSI UM sejak tahun 2013 sampai 2016 begitu memberi makna dan warna kehidupan selama menuntut ilmu di Malaysia. Kesulitan dan tekanan dalam tugas-tugas perkuliahan seakan dapat dilonggarkan oleh pertemuan dan kegiatan yang dilaksanakan. Hal ini dirasakan oleh pengurus dan yang terlibat didalamnya. Sehingga keakraban dan kekuatan ukhuwah dapat terjalin diantara pelajar-pelajar dan juga pekerja CS UM yang merupakan bagian dari rakyat Indonesia yang sedang mencarikan nafkah untuk keluarganya di Indonesia. 
Jurnal Pengabdian Masyarakat

vol.1 no.l Oktober 2017

\section{DAFTARPUSTAKA}

[1] Windy Anggraini. 2010. Melanjutkan Pendidikan di Luar Negeri Menuntut Ilmu atau Gengsi?. http://edisicetak.joglosemar.co/berita/melanjutkan-pendidikan-di-luarnegeri-menuntut-ilmu-atau-gengsi-7583.html[20 Desember 2016]

[2] Farah Ramadhani. 2016. Islam Liberal dan LGBT, sebuah diskusi intelektual. http://www.kompasiana.com/fabouus/event-islam-liberal-dan-lgbt-sebuah-diskusiintelektual_56cbdace5a7b61392196b6fb [21 Desember 2016] 